\title{
SPLIT TRANSPLANTATION OF THE TRACHEA: A NEW OPERATIVE PROCEDURE FOR EXTENDED TRACHEAL RESECTION
}

H. Yokomise, $\mathrm{MD}^{\mathrm{a}}$

K. Inui, $\mathrm{MD}^{\mathrm{a}}$

H. Wada, MD ${ }^{\mathrm{a}}$

M. Ueda, MD

S. Hitomi, $\mathrm{MD}^{\mathrm{a}}$

H. Itoh, $\mathrm{MD}^{\mathrm{b}}$
Before tracheal transplantation can be applied clinically, several problems must be solved: immunosuppression, blood supply to grafts, and reliable long-term preservation of grafts. We have conducted experiments on tracheal transplantation to solve these problems. In the present study, we tried a new operative procedure to accomplish reliable revascularization of transplanted tracheal grafts. It has been reported that transplantation of a 10-ring length of trachea is difficult even with omentopexy. Long tracheal allografts can be transplanted with use of direct revascularization, but this technique is extremely troublesome. Thus we developed a new operative procedure, "split tracheal transplantation," in which grafts are divided at the midportion and covered with omentum, after demonstrating that the blood supply to tracheal grafts can be reestablished around the suture lines. Two groups of dogs were used. In group A (control, $n=4$ ), a 10-ring length of trachea was autotransplanted. The anastomotic sites and grafts were covered with omental pedicles. In group B (split tracheal transplantation, $n=10$ ), tracheal grafts 10 rings Iong were autotransplanted. These grafts were divided at the midportion, a piece of omentum was inserted between the two halves, and the midportion was sutured. Grafts were observed regularly by bronchoscopy and examined histopathologically after the animals died or were killed. In some animals, microangiography of the bronchial circulation was done. In the control group, necrosis, stenosis, or malacia of the grafts was observed in three of the four animals. In the split transplantation group, all animals survived for at least $\mathbf{2}$ months, all grafts were incorporated, and none showed ischemia, stenosis, or malacia. Microscopic examination and microangiography revealed that neovascularization of the graft was promoted by omentum inserted at the midportion of the graft. Split transplantation of the trachea is an easy and reliable way to extend tracheal resection. (J Thorac Cardiovasc Surg 1996;112:314-8)
Trestis racheal transplantation has been one of the most challenging procedures for thoracic surgeons, and at least three problems must be solved before it is feasible clinically: immunosuppression, preservation of the tracheal graft, and vascularization of the graft. Most candidates for tracheal transplantation have malignant diseases, and immunosuppressive

From the Department of Thoracic Surgery, ${ }^{a}$ Chest Disease Research Institute, Kyoto University, and the Department of Radiology, ${ }^{b}$ Kyoto University School of Medicine, Kyoto, Japan.

Received for publication Nov. 10, 1995; accepted for publication Dec. 13, 1995.

Address for reprints: H. Yokomise, MD, Department of Thoracic Surgery, Chest Disease Research Institute, Kyoto University, 53 Shogoin-Kawaharacho, Sakyo-ku, Kyoto 606, Japan.

Copyright (c) 1996 by Mosby-Year Book, Inc.

$0022-5223 / 96 \$ 5.00+0 \quad \mathbf{1 2 / 1 / 7 1 1 6 5}$ agents must not be used. To solve this problem we developed new methods for immunosuppression. ${ }^{1,2}$ We have also achieved cryopreservation of the trachea for as long as 9 months. ${ }^{2,3}$ In the present study, we tackled the remaining problem: blood supply to the tracheal graft. In a preliminary experiment, we found that transplantation of a 10-ring length of trachea is not possible even with omentopexy, ${ }^{4}$ and we proved that the blood supply to tracheal grafts is reestablished around the suture lines and that revascularization is insufficient at the midportion of the graft if it contains 10 or more rings of trachea. Therefore we developed a new operative procedure, "split transplantation," in which grafts are divided at the midportion and an omental pedicle is introduced to improve local blood flow at three suture lines. 


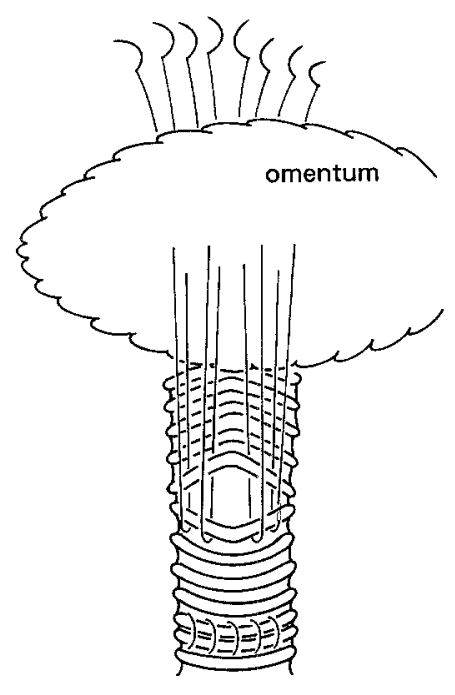

A.

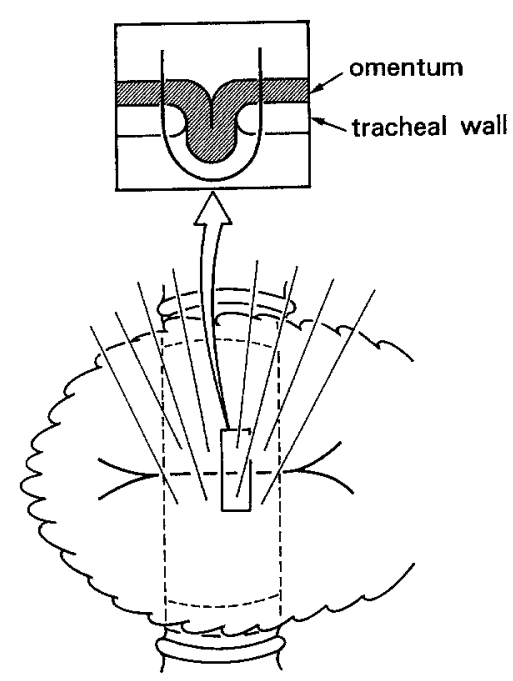

B.

Fig. 1. Diagram of split tracheal transplantation. A, Ten-ring length of trachea is autotransplanted. Grafts are divided at midportion and four to five 4-0 polypropylene sutures are placed through two halves of grafts and omentum. B, Omentum is inserted between two halves of grafts, and midportion is sutured.

\section{Material and method}

Animals and anesthesia. Adult mongrel dogs were used. After an intramuscular injection of ketamine and an intravenous injection of sodium thiopental, oral tracheal intubation was done, a Harvard pump (Harvard Apparatus Co., Inc., S. Natick, Mass.) was connected, and anesthesia was maintained with $50 \%$ oxygen, $50 \%$ nitrous oxide, and $1 \%$ halothane (Fluothane). The abdomen was opened through a midline incision, and an omental pedicle was prepared. Then a right thoracotomy was done, and a 10-ring length of mediastinal trachea was excised.

The animals were divided into two groups. In group $A$ (control, $n=4$ ), the tracheas were autotransplanted and fixed with 4-0 polypropylene continuous sutures (Prolene, Ethicon, Inc., Somerville, N.J.). The anastomotic sites and the grafts were covered with omental pedicles. In group B (split transplantation, $n=10$ ), sections of trachea 10 rings long were autotransplanted. The grafts were divided at the midportion and omentum was introduced between the halves. The anastomotic sites and the grafts were covered with omental pedicles as in the control group (Fig. 1). For 1 week after the operation, $1.0 \mathrm{gm}$ of cefazolin was injected intramuscularly every day.

Observation. The grafts were observed 1, 2, 3, and 4 weeks after the operation, then monthly. They were examined histologically at the time the animal died or was killed. Microangiograms of the bronchial circulation of three animals were taken (control group, postoperative day 158; split transplantation group, postoperative day 152 and postoperative day 158). After the administration of $5000 \mathrm{U}$ of heparin, dogs were killed by intravenous injections of potassium chloride. Barium sulfate was infused through the ascending aorta, and the microcircula-
Table I. Results of split transplantation study

\begin{tabular}{lrll}
\hline $\begin{array}{c}\text { Animal } \\
\text { No. }\end{array}$ & $\begin{array}{c}\text { Survival } \\
\text { (days) }\end{array}$ & $\begin{array}{c}\text { Status of } \\
\text { grafts }\end{array}$ & $\begin{array}{c}\text { Final } \\
\text { outcome }\end{array}$ \\
\hline Split transplantation group & & & \\
sp-1 & 60 & Incorporated & Killed \\
sp-2 & 175 & Incorporated & Killed \\
sp-3 & 217 & Incorporated & Killed \\
sp-4 & 175 & Incorporated & Alive \\
sp-5 & 174 & Incorporated & Alive \\
sp-6 & 168 & Incorporated & Alive \\
sp-7 & 162 & Incorporated & Alive \\
sp-8 & 158 & Incorporated & Killed \\
sp-9 & 152 & Incorporated & Killed \\
sp-10 & 152 & Incorporated & Alive \\
Control group & & & \\
c-1 & 7 & Necrosis & Killed \\
c-2 & 24 & Tracheomalacia & Killed \\
c-3 & 31 & Stenosis & Killed \\
c-4 & 158 & Incorporated & Killed \\
\hline
\end{tabular}

tion of the transplanted trachea was demonstrated roentgenographically.

The animals received humane care according to the guidelines set down in "The Guide for the Care and Use of Laboratory Animals" prepared by the Institute of Laboratory Animal Resources and published by the National Institutes of Health (NIH Publication No. 86-23, revised 1985).

\section{Results}

Survivors (Table I). In the control group, three of the four grafts lost viability. In the split transplan- 

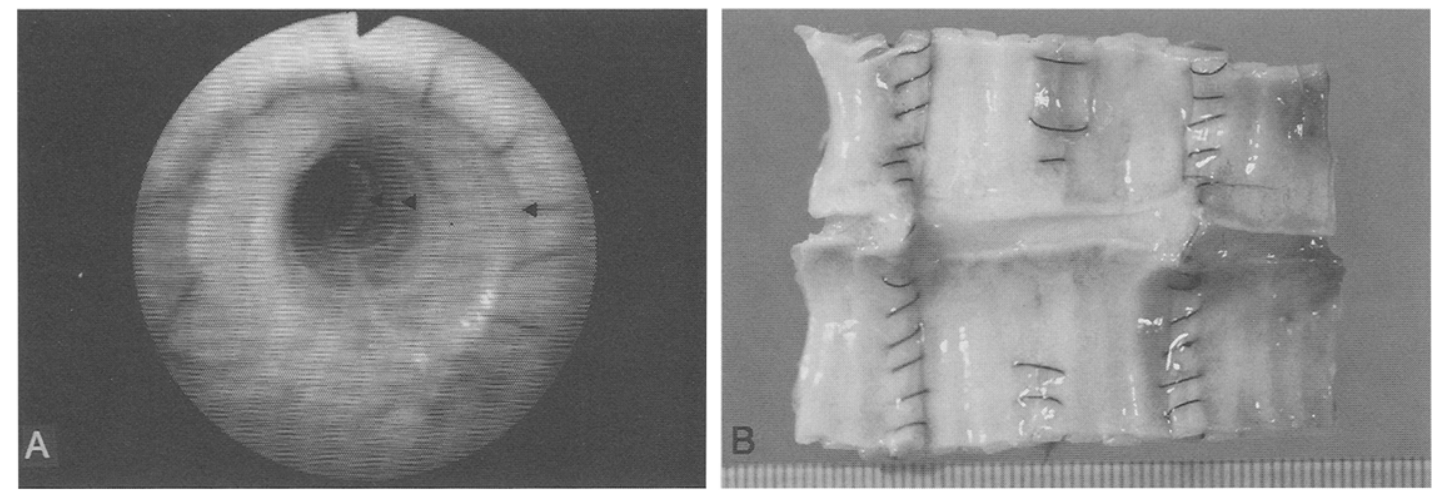

Fig. 2. Bronchoscopic (A) and macroscopic (B) findings 158 days after split tracheal transplantation. There is no stenosis at any anastomotic site (arrowheads) or in graft. There is no evidence of atrophy in graft.

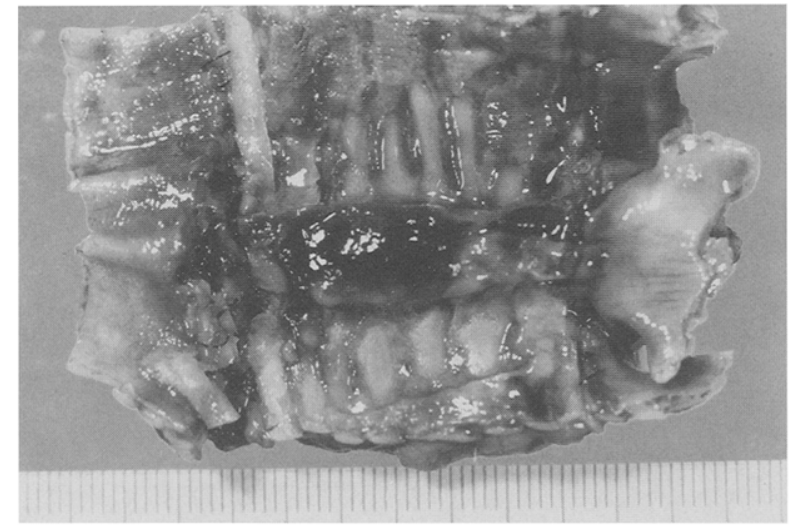

Fig. 3. Macroscopic findings 7 days after transplantation in animal from control group. Graft shows definite ischemic changes.

tation group, all grafts remained viable and all 10 animals survived for 2 months or longer.

Bronchoscopic and macroscopic findings. In the split transplantation group, all grafts were incorporated without stenosis, necrosis, or malacia. (Fig. 2, $A$ and $B$ ). Macroscopic findings 7 days after the operation showed ischemic changes of the graft in the control group (Fig. 3).

Histologic examination. In the animal in the control group that was killed 24 days after the operation, the epithelium of the graft was lost and the tracheal cartilage was almost absorbed. In the split transplantation group, the viability of the epithelium and cartilage was preserved. At the midportion of the graft, neovascularization was facilitated by the inserted omentum (Fig. 4).

Microangiography. In the split transplantation group, there was abundant neovascularization in the

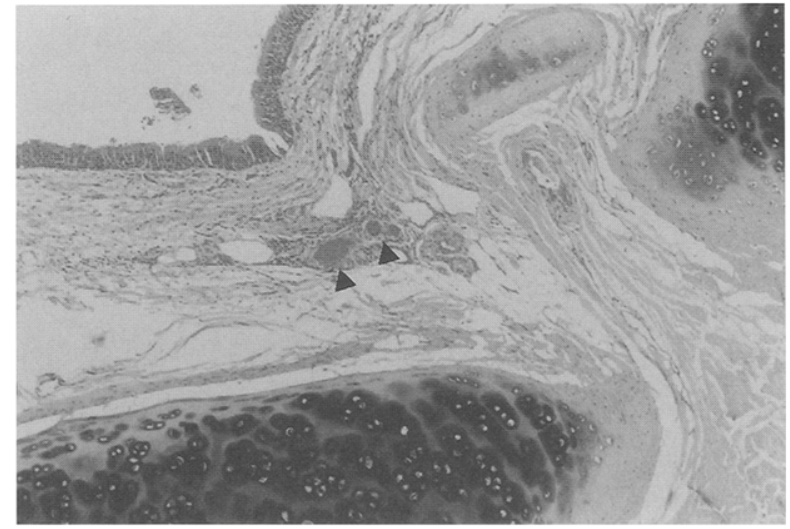

Fig. 4. Histologic findings after split transplantation. Viability of epithelium and cartilage is preserved. At midportion of graft neovascularization (arrowheads) has been facilitated by inserted omentum.

midportion of the graft (Fig. $5, A$ ), but neovascularization was poor at the midportion of the graft in the control group (Fig. 5, B).

\section{Discussion}

Recently clinical tracheal transplantation ${ }^{5}$ was done for the first time since 1979.6 A 24-year-old woman with severe tracheal stenosis caused by idiopathic mediastinitis received a $10 \mathrm{~cm}$ long tracheal allograft wrapped with omental pedicle. $\mathrm{Cy}-$ closporine and azathioprine were used for immunosuppression. However, the graft became necrotic, presumably because of rejection and ischemia, 10 days after the operation and a silicone stent was finally introduced. In this case, graft ischemia was the major problem.

In the present study, we found that omentopexy 

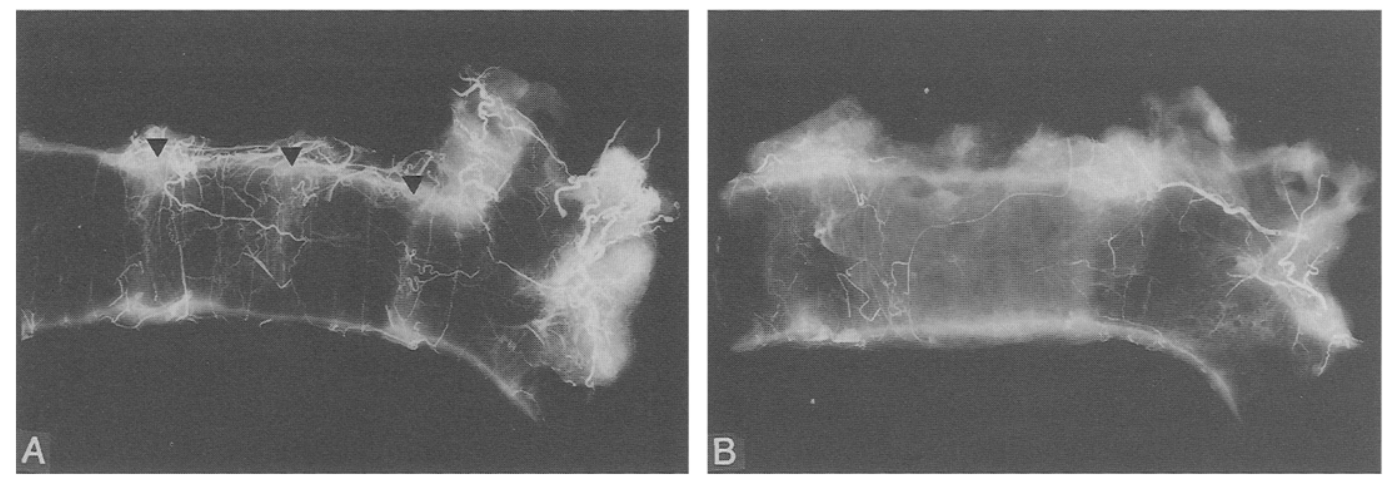

Fig. 5. A, Microangiogram of trachea 158 days after split transplantation. Abundant neovascularization of graft is present at all three anastomotic sites (arrowheads). B, Microangiogram of trachea from animal in control group 158 days after transplantation. Neovascularization is poor in midportion of graft.

was not enough to maintain the viability of the graft after 10-ring tracheal transplantation. In these dogs, ischemia was most pronounced at the midportion of the graft and there were no ischemic changes at the anastomotic sites as Nakanishi, Shirakusa, and Mitsudomi ${ }^{7}$ had reported. These findings indicated that early restoration of blood supply to the grafts probably occurs around the suture lines, so some additional procedure is required when a long tracheal graft is transplanted with omentopexy.

Salassa, Pearson, and Payne ${ }^{8}$ studied the details of the gross and microscopic blood supply to the trachea and found that the microcirculation of the trachea is maintained by lateral longitudinal anastomoses on both lateral walls of the trachea and anterior transverse intercartilagenous arteries that communicate with both lateral longitudinal anastomoses. The anterior tracheal wall is supplied by anterior transverse intercartilaginous arteries, and this area has a naturally poor blood supply. Therefore the anterior wall of the trachea is vulnerable to ischemic injury after tracheal transplantation and early restoration of the lateral longitudinal anastomoses and anterior transverse intercartilaginous arteries are extremely important when a long tracheal graft is transplanted. To meet this need, we developed a new operative procedure, split tracheal transplantation, in which grafts are divided at the midportion and omentum is inserted. Thus revascularization is facilitated at three anastomotic sites (two original and one central).

In fact, this procedure worked well and preserved the viability of transplanted grafts. Bronchoscopic examination revealed no stenosis, necrosis, or malacia of the grafts in any of the animals in the split transplantation group. Microscopic and microangiographic examinations showed that revascularization of the anterior tracheal wall was enhanced by the inserted omental pedicle. The grafts in most of the control animals did not remain viable. It is obvious that pedicled omentum is useful in improving the local microcirculation, ${ }^{9,10}$ but it cannot preserve the viability of long tracheal grafts.

Recently, tracheal transplantations with direct revascularization have been done successfully. ${ }^{11,12}$ However, these experiments are somewhat complicated, and obstruction of the reconstructed artery would result in immediate necrosis of the graft. On the other hand, split transplantation is an easy procedure, and it is unlikely that the entire microvasculature would be occluded at the same time. In another approach the local application of basic fibroblast growth factor has been tried, ${ }^{13,14}$ but the results are controversial. ${ }^{13}$

We have already reported that our own immunosuppressive therapy ${ }^{2}$ and preservation method ${ }^{2,3}$ are clinically applicable. The combination of these procedures and split transplantation will make clinical tracheal transplantation possible in the near future.

\section{REFERENCES}

1. Yokomise $H$, Inui $\mathrm{K}$, Wada $\mathrm{H}$, et al. High-dose irradiation prevents rejection of canine tracheal allografts. J Thorac Cardiovasc Surg 1994;107:1391-7.

2. Yokomise H, Inui.K, Wada H, Ueda M, Hitomi S. Long-term cryopreservation can prevent rejection of canine tracheal allografts with preservation of graft viability. J Thorac Cardiovasc Surg 1996;111:930-4.

3. Yokomise $\mathrm{H}$, Inui $\mathrm{K}$, Wada $\mathrm{H}$, Hasegawa $\mathrm{S}$, Ohno N, Hitomi S. 
Reliable cryopreservation of trachea for one month in a new trehalose solution. J Thorac Cardiovasc Surg 1995;110:382-5.

4. Yokomise $\mathrm{H}$, Inui $\mathrm{K}$, Wada $\mathrm{H}$, Hitomi S. The infeasibility of using ten-ring irradiated grafts for tracheal allotransplantation even with omentopexy. Surg Today. In press.

5. Levashov YN, Yablonsky PK, Cherny SM, Orlov SV, Shafirovsky BB, et al. One-stage allotransplantation of thoracic segment of the trachea in a patient with idiopathic fibrosing mediatinitis and marked tracheal stenosis. Eur J Cardiothorac Surg 1993; 7:383-6.

6. Rose KG, Sesterhenn K, Wustrow F. Tracheal allotransplantation in man. Lancet 1979;1:433.

7. Nakanishi R, Shirakusa T, Mitsudomi T. Maximum length of tracheal autografts in dogs. J Thorac Cardiovase Surg 1993; 106:1081-7.

8. Salassa JR, Pearson BW, Payne WP. Gross and microscopical blood supply of the trachea. Ann Thorac Surg 1977;24:100-7.

9. Inui $\mathrm{K}$, Wada $\mathrm{H}$, Yokomise $\mathrm{H}$, et al. Evaluation of a bronchial anastomosis by laser Doppler velocimetry. $\mathbf{J}$ Thorac Cardiovasc Surg 1990;99:614-9.
10. Hirata $T$, Yamazaki $F$, Fukuse $T$, et al. Omentopexy for revascularization of free tracheal grafts in rats. Thorac Cardiovasc Surg 1992;40:178-81.

11. Khalil-Marzouk JF. Allograft replacement of the trachea: experimental synchronous revascularization of composite thyrotracheal transplant. J Thorac Cardiovasc Surg 1993;105: 242-6.

12. Macchiarini P, Lenot B, Vincent de Montpreville, et al. Heterotopic pig model for direct revascularization and venous drainage of tracheal allografts. J Thorac Cardiovasc Surg 1994;108:1066-75.

13. Olech VM, Keshavjee SH, Chamberlain DW, Slutsky AS, Patterson GA. Role of basic fibroblast growth factor in revascularization of rabbit tracheal autografts. Ann Thorac Surg 1991;52:258-64.

14. Mayer E, Cardoso PFG, Puskas JD; et al. The effect of basic fibroblast growth factor and omentopexy on revascularization and epithelial regeneration of heterotopic rat tracheal isografts. J Thorac Cardiovasc Surg 1992;104: 180-8.

\section{Bound volumes available to subscribers}

Bound volumes of The Journal of Thoracic and Cardiovascular Surgery are available to subscribers (only) for the 1996 issues from the Publisher, at a cost of $\$ 100.50$ for domestic, $\$ 128.94$ for Canadian, and $\$ 120.50$ for international subscribers for Vol. 111 (January-June) and Vol. 112 (July-December). Shipping charges are included. Each bound volume contains a subject and author index and all advertising is removed. Copies are shipped within 60 days after publication of the last issue of the volume. The binding is durable buckram with the Journal name, volume number, and year stamped in gold on the spine. Payment must accompany all orders. Contact Mosby-Year Book, Inc., Subscription Services, 11830 Westline Industrial Drive, St. Louis, Missouri 63146-3318, USA; phone $800-453-4351$ or $314-453-4351$.

Subscriptions must be in force to qualify. Bound volumes are not available in place of a regular Journal subscription. 